\title{
Innovation potentials for construction materials with specific focus on the challenges in Africa
}

\author{
Wolfram Schmidt ${ }^{1}$, Mike Otieno ${ }^{2}$, Kolawole Adisa Olonade ${ }^{3}$, Nonkululeko W. Radebe ${ }^{4}$, Henri van Damme ${ }^{5}$, \\ Patience Tunji-Olayeni ${ }^{6}$, Said Kenai ${ }^{7}$, Angela Tetteh Tawiah ${ }^{8}$, Kuukuwa Manful $^{9}$, Akeem Akinwale ${ }^{3}$, \\ Rose N. Mbugua ${ }^{10}$, Andreas Rogge ${ }^{1}$
}

\author{
${ }^{1}$ Bundesanstalt für Materialforschung und -prüfung, Germany \\ ${ }^{2}$ University of the Witwatersrand, South Africa \\ ${ }^{3}$ University of Lagos, Nigeria \\ ${ }^{4}$ Karlsruher Institut für Technologie, Germany \\ ${ }^{5}$ The Joint CNRS-MIT Laboratory, USA \\ ${ }^{6}$ Covenant University, Nigeria \\ ${ }^{7}$ Université Blida 1 \\ ${ }^{8}$ MC Bauchemie Ghana \\ ${ }^{9}$ SOAS University of London, UK \\ ${ }^{10}$ Walter Sisulu University, South Africa
}

Received: 02 June 2020 / Accepted: 23 September 2020 / Published online: 05 October 2020

(C) The Author(s) 2020. This article is published with open access and licensed under a Creative Commons Attribution 4.0 International License.

\begin{abstract}
Africa is urgently in need of adequate basic infrastructure and housing, and it is one of the continents where massive construction activities are on the rise. There is a vast variety of potentially viable resources for sustainable construction on the continents, and consequently, the continent can bring innovative, greener technologies based on local sources effectively into practice. However, unlike established concrete constituents from industrialised countries in the global North, most of the innovation potentials from the African continent have not yet been the focus of intensive fundamental and applied research. This clearly limits the implementation of more sustainable local technologies.

This paper presents a case for the need to first appreciate the rich diversity and versatility of the African continent which is often not realistically perceived and appreciated. It discusses specific innovation potentials and challenges for cementitious materials and concrete technology based on local materials derived from sources on the African continent. The unique African materials solutions are presented and discussed, from mineral binders over chemical admixtures and fibres to reinforcement and aggregates. Due to the pressing challenges faced by Africa, with regards to population growth and urbanisation, the focus is not only put on the technological (durability, robustness and safety) and environmental sustainability, but also strongly on socioeconomic applicability, adaptability and scalability. This includes a review of alternative, traditional and vernacular construction technologies such as materials-saving structures that help reducing cementitious materials. Eventually, a strategic research roadmap is hypothesised that points out the most relevant potentials and research needs for quick implementation of more localised construction materials.

Keywords: Urbanisation; Sustainability; Materials research; Cement; Concrete
\end{abstract}

\section{Introduction}

Construction materials have enormous direct and indirect impact on the global climate, not only for the huge energy consumption but also the massive emissions of greenhouse gasses. Cement production alone consumes a high volume of virgin raw materials, is energy intensive and involves chemical process technologies that pollute the environment. Thus, it contributes significantly to global $\mathrm{CO}_{2}$ emission. Global cement production was estimated at $4.6 \mathrm{Gt} / \mathrm{a}$ [1] in 2015 and continues to rise to expected values between 6 and $13.5 \mathrm{Gt} / \mathrm{a}$ in 2050 [2, 3]. While cement production in China has reached its maximum peak, the production in other emerging countries is expected to grow from the current $26 \%$ to $37 \%$ in 2050 [4]. This is because mineral binders such as cement are an essential component of concrete, which is the material used to build structures and infrastructures in the rapidly developing global South as well as for maintenance and retrofitting of the built environment in developed countries of the global North.

To date, concrete is the only material in the world that can meet the enormous global demand for construction materials [4]. Any other materials used in the same quantity would generate much higher carbon emissions and require more processing energy [5]. Nevertheless, concrete is produced in

\footnotetext{
* Corresponding author: Wolfram Schmidt, Email: wolfram.schmidt@bam.de
} 
huge volumes - it makes out approximately $50 \%$ by mass of everything that the world produces - and therefore it significantly contributes to global carbon emissions. Cement alone is responsible for about 6 to $10 \%$ [4] and additional contributions arise from manufacture, transportation and construction itself. The situation is aggravated by the projected increase in the world's population from today's 7.3 to 9.7 billion in 2050 [6], which leads to an increase in demand for housing and infrastructure. This, in turn, results in a direct increase in the demand for concrete. This growing demand has dramatic consequences for the global climate [4] and as recently concluded by a Consensus of leading international institutions of the built environment such as JCSS, RILEM, IABSE, fib, CIB, ECCS [7], sustainable innovation at all level is urgently required.

In the light of this, Africa becomes the region in the world where sustainable innovation can have the greatest leverage towards mitigation of the climate challenge, if strategic actions be taken rapidly. The rate of population growth in African urban regions is on average more than twice that of the rural areas [8]. By 2050 today's urban construction in Africa will be quintuplicated [9], which will ideally take place using sustainable, materials-saving, and environmentally friendly technologies. However, since sustainable materials inevitably call for local solutions fit for the specific purpose and adapted to the specific boundary framework $[8,9]$, more research in unknown or under-investigated alternative resources and technologies is urgently required.

African research should focus on technologies that help keeping the carbon emissions low. Today, Africa accounts for only ca. $4.2 \%$ of global carbon emissions (Fig. 1a.), while the per capita carbon emissions in Sub-Saharan Africa (SSA) are less than $5 \%$ of the emissions of a US citizen. Considering a proposed annual carbon budget of $2.7 \mathrm{kt}$ per capita to limit the global warming to $2{ }^{\circ} \mathrm{C}$ [10], SSA is the only region in the world that can stay below this threshold coming from significantly below it (Fig. 1b.). The numbers for the Figs. 1a and $1 \mathrm{~b}$ were calculated based on country data from 2018 provided by [11], which were sourced from Carbon Dioxide Information Analysis Center, Environmental Sciences Division, Oak Ridge National Laboratory, Tennessee, United States. This low per capita carbon budget gives Africa an enormous potential, but also a high responsibility to become a global green pioneer. In order to make this possible, research in the relevant areas is inevitable.

The numbers in Fig. 2a were calculated based on country data for 2018 taken from [13], which were sourced from National Science Foundation, Science and Engineering Indicators. Similar numbers were shown by other sources in 2015 [14]. The percentage of SSA is just a bit higher than that of Switzerland (0.933\%), although SSA has 125 times more inhabitants. Switzerland is a country with a per capita GDP of 79214 USD in 2018, which is between 5.4 and 376 times higher than the highest and the lowest African national per capita income for the Seychelles with 14385 USD and Burundi with 211 USD, respectively [15].

\section{Percentage of total global carbon} emissions, 2018

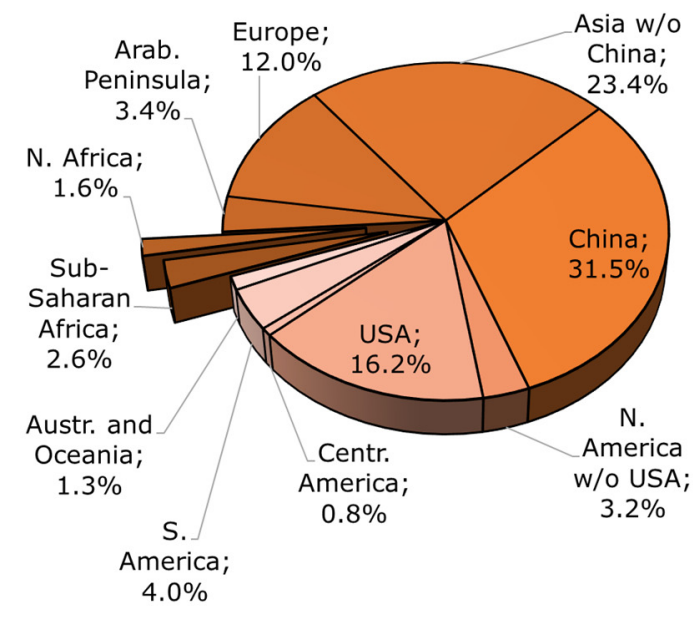

Annual per capita $\mathrm{CO}_{2}$-emissions,

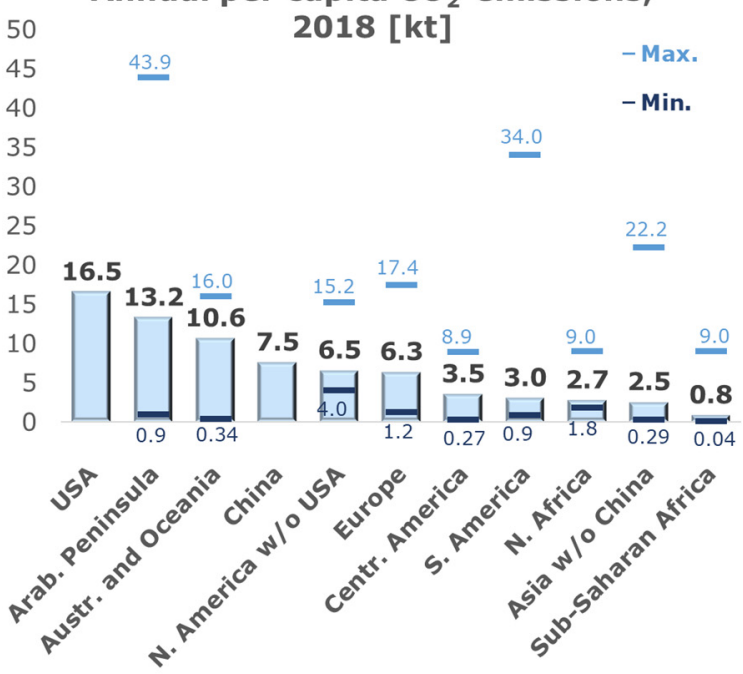

Figure 1. Percentage contribution of different regions to the global carbon emissions (a) and per capita carbon emissions for the respective regions (b) (data source [11]).

Therefore, Switzerland can afford spending 2670 USD per capita to be invested in research. In contrast, NA on average spends 20.4 USD per capita expenses in research and SSA on average 6.8 USD. South Africa spends the maximum, which is 60.96 USD and Madagascar spends the minimum, which is 0.05 USD (Fig. 2b). The numbers in Fig. $2 b$ were calculated by dividing the total regional research expenditure with the total regional population. Regional data were derived from country data provided by [16] based on UNESCO Institute for Statistics; regional population data were derived from country-specific data provided by [12] based on United Nations Population Division, national statistical offices, Eurostat, and United Nations Statistical Division. 
Scientific journal output from respective region, $2018[\%]$
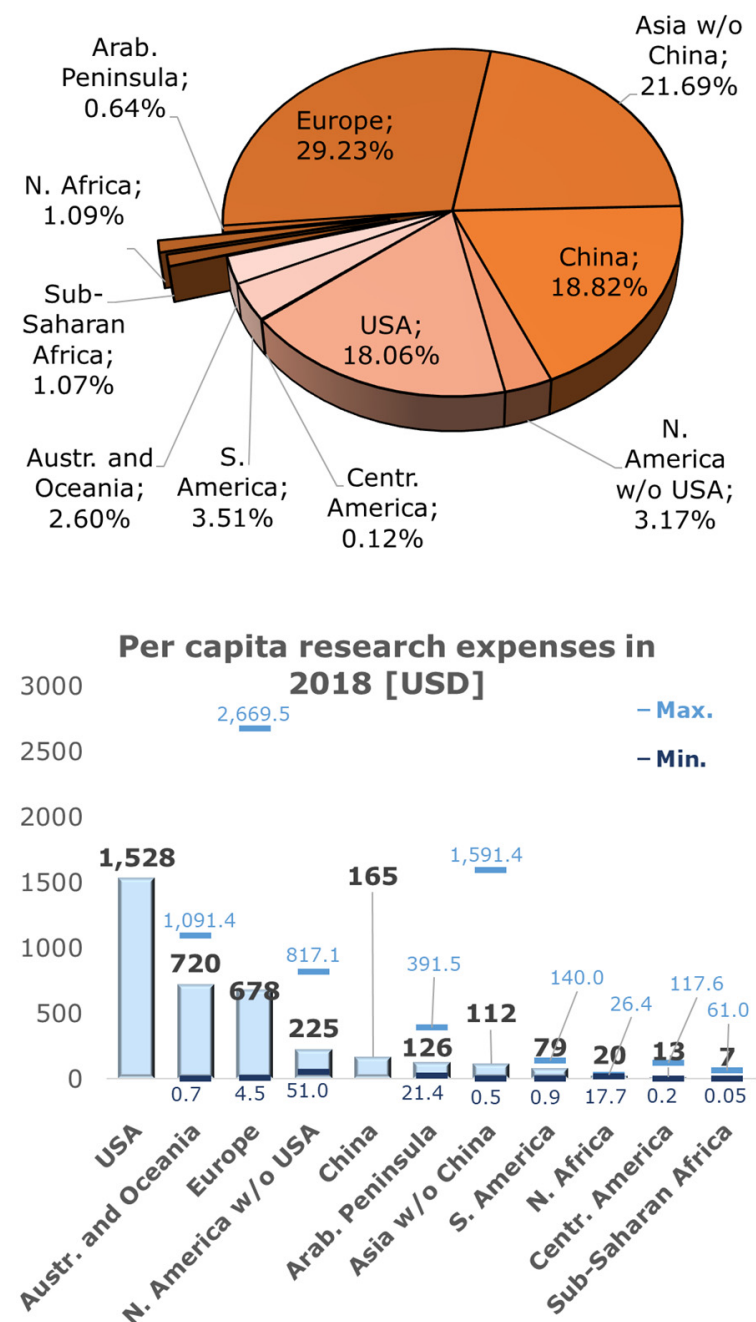

Figure 2. Scientific and technical journal output indexed in $\mathrm{SCl} / \mathrm{SSCl}$ from different regions in the world (a) (data source: [13]), and per capita research expenses in these regions (b) (data sources: $[12,16]$ ).

The low investment in research in Africa is mainly due to the need to meet almost equally competing basic demands such as food, health, education and infrastructure development, using limited income. Therefore, it is likely that the limited financial support for research in Africa will continue to be the case for the next couple of decades, while at the same time, the demand for rapid urban growth and infrastructure will increase dramatically and calls for research progress.

With limited financial resources for research in Africa, it becomes more relevant than for any other group of researchers to concentrate on activities and projects that have the maximum social impact. Researchers in Africa need to channel and combine research capacity in those specific areas that not only address local challenges but also have global impact.

The socio-economic, cultural and historic African research perspectives are globally extremely relevant and should have greater impact in the world. Nevertheless, research in construction and construction materials stands out because of the dramatic climatic threats, the consequences of which will affect the whole world. The urbanisation pressure along with Africa's unique offset position in terms of per capita carbon emissions make research in sustainable, locally sourced, and greener construction materials eminent. It is also important to notice that materials and construction have socio-economic, cultural, historic, and future determining components since building activities and human developments have always been mutually interacting [17]. Hence, research in these areas can also spark new research frontiers of social and cultural relevance. In return, African engineers and natural scientists should consider the social relevance and impact of their research. Even with limited financial resources and research output, such considerations should make research addressing Africa be appreciated in their own right relative to the other publications.

This paper proposes and advances a number of relevant and innovative potential research-based solutions in the field of construction materials with specific African and global relevance that goes beyond the purely technical aspects. The overview paper aims at inspiring and triggering future research activities within a broader context, including the link between materials and socio-economic implications, with relevance for more sustainable, climate friendly, and local construction.

\section{Specific African boundary conditions}

The African continent exhibits specific boundary framework that significantly differ from those conditions that can be found in regions where concrete looks back on a significantly longer tradition and history, such as Europe, North America and parts of Asia. This means, many existing rules and the often applied European or US standards are not ideal for the African framework. The boundary conditions within the African framework are as follows:

- In contrast to many other regions where the cost of cement is significantly lower than labour cost, in most African countries cement is often the most relevant cost in construction [18].

- $\quad$ Ready-mixed concrete is not common practice in most countries in SSA. The typically strained urban infrastructure makes transportation times unreliable and the costly long-distance transportation requirements to areas with poor accessibility demand for retarding admixtures. Despite the advantages of ready-mixed concrete over site mixed concrete [19], maximisation of its benefits will continue to be a challenge on the continent.

- Much of the construction industry is conducted within the informal sector which, depending on the country, makes out between $20 \%$ and $89 \%$ of the nonagricultural business in Africa [20]. 
- Apart from NA countries and South Africa, clinker, gypsum, admixtures and supplementary cementitious materials (SCMs) are often shipped into African countries from other countries and continents based on market prices, causing enormous scatter in constituents' quality. At the same time, they lack wellequipped and funded quality control laboratories. This hinders their ability to cope with the vast variability of products in the market, increasing the need for robustness in the application.

This special framework that deviates from most regions, where concrete has been established on larger scale than in Africa today, calls for non-conventional solutions - with regards to materials and technologies.

\section{Mineral binders}

Worldwide applied standards for cementitious materials consider fly ash (FA), limestone filler, and ground granulated blast furnace slag (GGBS) as SCMs to modify performances and minimise the clinker factor. However, FA and GGBS hardly exist on the African continent, and thus are not a viable option. Also calcined and natural pozzolana have been considered, but in order to find acceptance in the market, more research into their performance is required. Based on the proven effectiveness of these materials [4, 21], these materials can also become viable options in many regions in Africa to lower carbon emissions and reduce costs, particularly in the East African Rift Valley as well as in West Africa and North Africa. Nevertheless, the option of natural pozzolan could also compete with land in those areas where subsistence and commercial farming are predominant, while the challenge of disrupting the natural ecosystem with associated pollution call for concern.

Another widely unexplored potential source of supplementary materials is the mining industry. Mining is a very strong industrial sector in Africa, unfortunately with relatively little local added value. Exploring the possible use in the construction sector of the huge volumes of wastes produced by the mining activities may be a useful way to add value, provided the heavy metal content can be kept below the acceptable values [22]. Similarly, the large evaporite rock deposits found in some countries of East and West Africa may become a very valuable source of material for alkali-activated binders.

Furthermore, limestone calcined clay cement (LC3) is a rapidly emerging technology [4, 21]. LC3 can be produced from so called dirty clays, which are not suitable for the ceramics industry. If these clays are calcined they become more reactive and show a synergistic effect with limestone, which can significantly reduce the clinker factor. Africa has huge deposits of clay, and the high clinker prices in most African countries call for solutions where cost can be saved along with carbon emissions.

Another relevant source of binder alternative comes from agriculture such as the ashes of many by-products from food processing such as cassava peels, rice husks, sugar cane bagasse, palm kernel or maize cobs [23-29]. A major limiting factor for the large-scale use of these wastes, which are often produced by smallholders or cooperatives, is the relatively small amount as well as the lack of infrastructure to collect, monitor, control and homogenise the residues for further industrial use. Therefore, the use of these materials in cement plants is not economically viable in most places. Nevertheless, ternary blending of the ashes from agro-based materials can increase the supply and substantially reduce clinker consumption. Meanwhile, more research is needed to establish performance of ternary blends. Furthermore, the African cement market consists of multiple players, including many formal and informal smallholder brick producers, that can make use of the bio-based pozzolans to reduce cement for cost saving and to improve their carbon footprint. Using agricultural waste, in this way, offers additional benefit of being effective disposal, minimising environmental challenges faced by the current disposing techniques in most African countries.

In addition, materials such as natural gypsum and phosphogypsum which are, respectively, available in large reserves and produced as by-products from the phosphate industry in large quantities in Africa [30,31], can be incorporated with little processing in the construction of affordable housing. The use of gypsum should be explored especially in the hot and dry regions such as North Africa and Sahel in order to exploit its heat and sound insulation properties in such areas. Phospho-gypsum can be used in the brick and cement industry, and in road construction [32].

With the right resources and a circular approach, a combination of pyrolysis and vertical shaft kiln technology would allow to produce organic components to be used as admixtures or sealants before in a next step mineral pozzolanic materials could be produced along with the production of bricks and calcined clays [8]. Research in circular and synergistic production processes requires significantly more collaborative research between civil, process, and environmental engineering.

\section{Chemical admixtures for concrete}

Water reducing agents have revolutionised the concrete technology as they help to reduce the water content in concrete without compromising the consistency. This, in conjunction with supplementary chemical admixtures such as retarders, accelerators and stabilising agents, eventually, led to the development of new concrete types, the consistency of which can be tailored to the specific process requirements. In Africa the use of chemical admixtures is probably more important than in many other regions in the world due to the high temperatures as well as the wide range of construction site environments from minimalistic equipment to fully automated process chains.

However, most chemical admixtures used in concrete are based on naphtha chemistry, and the global processing typically takes place outside Africa. Therefore, most of the chemical admixtures are imported. This makes the use of chemical admixtures economically and environmentally challenging.

Recent studies have shown that alternatives to the established chemical admixtures exist, mostly based on 
polysaccharides [33-38]. Besides agents such as starch and cellulose that are largely known products to modify the viscosity of concrete and grout, other polysaccharides than can be derived from by-products of food production or directly harvested from nature have shown great potentials to modify the rheological properties of cementitious systems.

- The starch of cassava has pointed out to have moderate plasticizing effect [23]. Since chemical admixtures are typically added at low dosages to concrete, the starch residues adhered to the peels can be used to derive construction chemicals, so that the full tuber can be used for food processing.

- Acacia gum can be a very efficient water reducing agent, which can outperform commercial polycarboxylate ethers. The performance of the gum, however, depends significantly on the region where it grows as well much more than established plasticizers on the water to solid ratio [37-39]. Hence, further research in the robust application of such gum is required.

- The gum of the bark of Triumfetta pendrata A. Rich pointed out to dramatically increase the thixotropy of cement paste in combination with plasticizing admixtures [37, 40,41]. While the gum alone slightly increases the plasticity of cement pastes, in combination with supplementary plasticizing admixtures, it can create flowable consistency that converts into a fully thixotropic structure after just a few minutes [40], thus qualifying for a variety of special applications, such as sprayed concrete, rendering, or even 3D printing.

Many effects on the rheological properties can be explained by polymer properties such as hydrodynamic radii, molecular weights, and zeta potentials, but there is a wide variability of performances, due to fertilizers, time of harvest, processing, soil and other effects that need to be studied to make their application more robust.

Plasticizers, stabilizing agents, thixotropy agents based on locally sourced polysaccharides such as acacia gum, cassava starch and the gum of triumfetta pendrata $A$. Rich are only a few examples of application possibilities that can be found if further research is put in polysaccharides. Due to its biodiversity, Africa, thus, has an enormous opportunity to develop novel and low-cost admixtures. They are environmentally friendly and sustainable as well as economically viable. Research activities in this area are just in their infancy, and African researchers could spearhead this bio-based path. Research activities have to be at the threshold between civil engineering, materials technology, chemistry and physics.

\section{Local aggregates, fibres and reinforcement}

Aggregates constitute between $70 \%$ and $85 \%$ by volume of concrete. The wide variety of the minerology of natural aggregates demand for intensive research in aggregates.

Lightweight aggregates can help reduce the dead weight, and thus cement and materials in general. However, for larger buildings, live loads typically dominate the loading effect, and thus the savings due to the use of lightweight aggregates are limited. Yet, often lightweight materials improve the thermal insulation, which is important in the hot and humid regions in Africa.

Large parts of Africa are covered by desert especially in the poorest Sahel countries. The Sahara alone makes out about $30 \%$ of the continent. Dune sand is readily available in the expansive desert regions in Africa (e.g. the Sahel countries) with reduced need for extraction and processing. Laboratory tests have shown that dune sand is suitable for use in ordinary and self-compacting concrete as well as in sand concrete and repair mortar [42] but more research is required on industrial use.

The use of alternative agro-based aggregates in Africa should also not be ignored considering the abundant agricultural byproducts in Africa [43, 44]. Plant-based fibres and reinforcement can be used to enhance mechanical properties of construction materials including concrete. For example, plant-based fibres have been reported to have the potential to increase the cracking resistance and enhance the postcrack behaviour of cement-based construction materials [45, 46]. Although the supply of fibres is limited [47] compared to the enormous concrete demand, the available fibres such as sisal, flax, hemp, coconut coir, kenaf, palm tree, and others can be selectively used in the manufacture of special cementitious materials such as renders, repair mortars and grouts. Combinations could also become interesting. Krobba et al. have used a combination of DS and fibres of Stipa tenacissima to produce a low cost environmentally friendly repair mortar [48]. Research is still needed to study other similar combinations for different environmental exposure conditions.

Finally, Bamboo is an interesting reinforcement material in concrete technology. One tenth of the global land areas, where bamboo is grown, are located on the African continent, half of which in Ethiopia [49]. Bamboo can be used as reinforcement [50-52] while bamboo waste ashes would also qualify as pozzolanic cement replacements $[53,54]$.

Interested readers can refer to the published works of RILEM Technical Committee 236 on Bio-based Building Materials (www.rilem.net) for more details on the properties and use of natural fibres and aggregates.

\section{Materials-saving structures}

Rapid urbanisation inevitably leads to taller high-rise structures. The need to slow down global warming as well as the high construction costs demand for materials-saving technologies. In this context, the fact that most urban buildings required to cater for the growing population still have to be built is a great opportunity for urban planners and structural designers to explore materials-saving designs and optimised use of materials.

In situations of rapid urban growth, real estate rapidly increases in value, which drives the construction of taller highrise structures in order to maximise on the use of the limited land-area and return on investment. However, from an environmental perspective, taller structures are not ideal. 
Since each storey in a high-rise building has to carry the sum of the storeys above, vertical growth rapidly leads to wastage of materials for vertical elements [55]. But there are more structural parameters that affect the material requirement.

Fig. 3 shows an example of a calculation for the overall material requirement of multi-storey structures relative to the material requirement for the same number of elements without being stacked on each other. The sample uses common design equations for the dimensioning known from textbooks. A simple structure is assumed for this example. It has uniaxial single span floor slabs placed on single span beams of $0.25 \mathrm{~m}$ breadth, which are supported by columns, where the span for the slabs and the beams are equal. The figure shows different parameter variations in comparison to a reference structure with a span width of $5 \mathrm{~m}$ and a density of $2500 \mathrm{~kg} / \mathrm{m}^{3}$. The reinforcement was assumed to be $0.45 \%$ for the slabs and $1.5 \%$ for the beams. The design steel strength in the sample is $286 \mathrm{MPa}$, and the static height is assumed to be $5 \mathrm{~cm}$ and $8 \mathrm{~cm}$ shorter than the calculated height for the cross section for the slab and the beam, respectively. The lever arm for internal forces was assumed as $85 \%$ of the effective depth. The live load was fixed to $2 \mathrm{kN} / \mathrm{m}^{2}$, and all horizontal load cases as well as specific aspects such as bearing pressure or punching forces were ignored. This academic example is supposed to serve as an indication, independently of standards and design tables, where in a structures extraordinarily high cross sections are necessary and material savings can be achieved by varying materials and structural parameters.

In all cases, the overall material demand increases with increasing number of storeys due to the larger cross sections required for the vertical elements. At 50 storeys, the additional material requirement varies between $3 \%$ and $11 \%$. Much more influence can be found from the span width. The increase of the span from 5 to $6.25 \mathrm{~m}$ already increases the material demand by approximately $30 \%$, while a span of $12.5 \mathrm{~m}$ already more than double the materials demand. These high numbers indicate that for the sake of material savings, architectural compromises might be required and more mutual cooperation between architects and structural designers has to be encouraged.

Increasing strength does not have a significant material saving effect. The reason is that in the dimensioning of beams and slabs the concrete strength play a less significant role for the cross section. Nevertheless, higher concrete strength causes that the extra material demand for higher structures increases to lower degree relative to the case of lower strength concrete relatively reduces the increase of material demand due to higher numbers of storeys. Nevertheless, the lower material demand in case of 50 storeys with higher strength concrete relative to the lower strength concrete should be considered with care, because higher strength typically comes along with higher cement demands, which in return increase the environmental footprint of these types of concrete $[56,57]$. A recent material parameter study on 14 , 30 , and 60 storey structures has shown that high strength concrete could only help reducing the carbon footprint in the
60 storey structure [58], while at lesser storeys, lower strength concrete had lower environmental impact.

Using concrete with lower density also helps reducing the material demand up to $9 \%$ in the ten-story case and about $5 \%$ in the 50-storey case. However, it has to be considered that typically, lower density comes along with lower strength, or it has to be compensated with higher cement demand. Therefore, the application of lower density material has to be discussed more specifically and depending on the full concrete mix design.

This example shows some material and structural dependent parameters that need combined consideration for overall material reduction and reduction of the carbon footprint. The specific African framework with high material and relatively low labour costs, demands for alternative structural dimensioning approaches, where material saving without compromising the safety, is given special consideration. Future researchers should, thus, focus more on the interface between materials performances, and structural behaviour to develop structures that are optimised for minimum material requirements and carbon emissions.

In this context, structural engineers should also develop new approaches how static requirements and durability considerations can be conducted more holistically. Often the durability related design criteria yield significantly higher strengths than structurally required. Research into concepts that consider both aspects jointly as proposed by [59] could become more important in the future.

For architects, considerations about sustainability might require the acceptance of clearance limitations, which may be perceived as limitation of the architectural degrees of freedom. Nevertheless, Fig. 3 clearly shows that smaller spans can save significant amounts of materials. It is a general problem, that sustainable architecture by design limitations are typically not directly visible to become appreciated by the public. Therefore, research in architecture should also focus on how, sustainable architecture can become more tangible to the people. The development of architectural styles that expose the supporting structural elements and the beauty of material combinations rather than concealing them, could create better grasp of the public for sustainable architectural design.

\section{Alternative, traditional and vernacular construction}

Due to the lack of viable alternatives for large scale construction, concrete is one of the best construction materials for mass construction in urban settlements. However, as the preceding sections have shown, saving cement and other materials is another important aspect in construction in several African contexts. This, therefore, calls for using cement only where it is structurally required, and considering the vast variety of alternatives for non-structural applications. Structural designers and architects have to continue to develop concepts where material combinations are optimised according to their specific behaviours. 

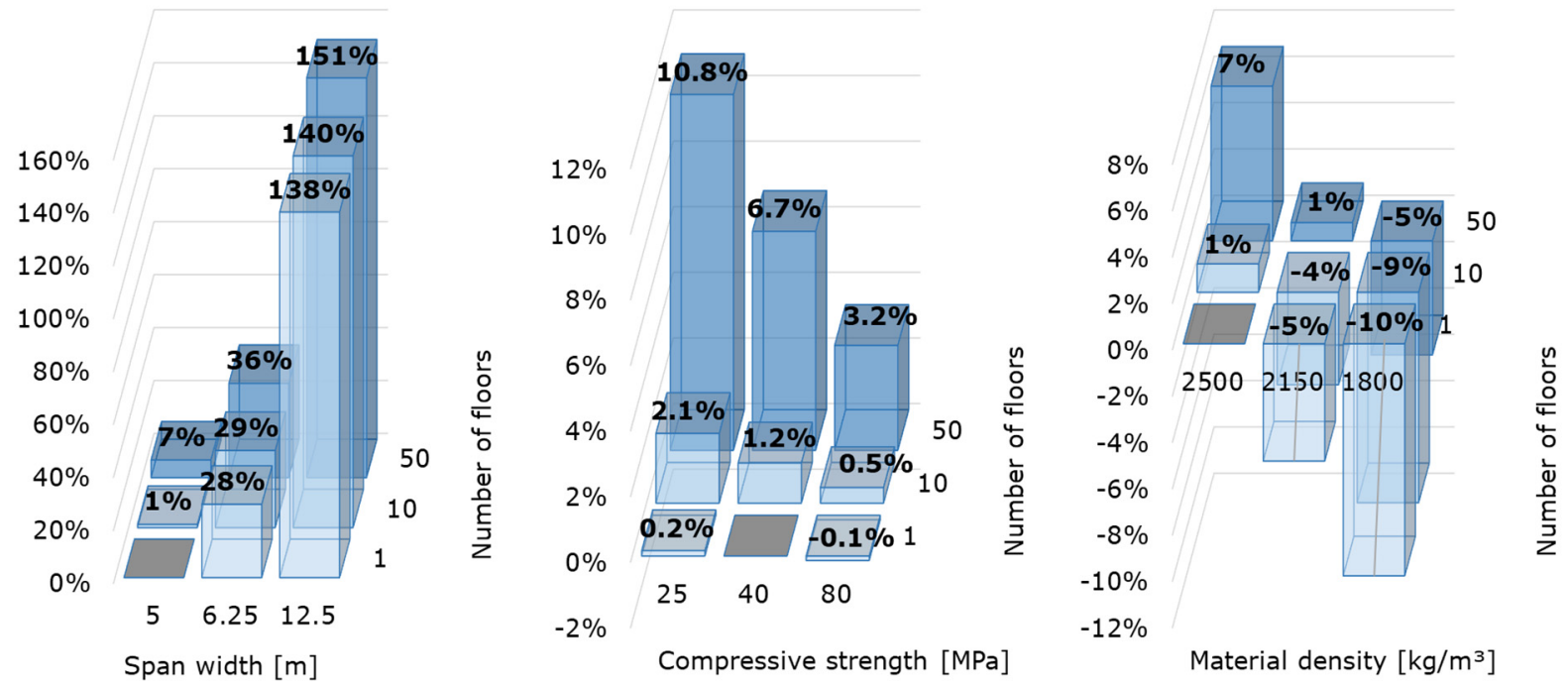

Figure 3. Percentage of additional or less material demand relative to a reference single storey structure $\left(\mathrm{span}=5 \mathrm{~m}, \rho=2500 \mathrm{~kg} / \mathrm{m}^{3}, \mathrm{q}=2 \mathrm{kN} / \mathrm{m}^{2}\right.$, $\sigma=40 \mathrm{MPa}$ ) depending upon number of stacked storeys, and parameter changes of the span width, the compressive strength, and material density.

The global South and Africa are extraordinarily diverse showrooms of resourceful and economical answers to local material and environmental constraints. This intrinsically vernacular character of traditional habitat construction materials and techniques - to use with measure what is locally available and recyclable and invent locally optimised solutions - is contrasting with the evolution of the modern habitat construction sector, privileging a limited choice of standardised and globalised materials and construction solutions.

In this context, it is urgent to re-visit vernacular materials and constructive cultures and to extract the key concepts which are the result of centuries of applied research and which have proven their raison-d'être based on the experience of former master builders [9]. Equally urgent is the need to broaden the spectrum of criteria used to scrutinise materials and methods. As we move toward a circular economy, full cradle-to-cradle - and not cradle-to-grave -recyclability may become as important as durability, if not more [7]. Social inclusiveness and resonance with local culture should be considered on an equal footing with strictly technical and environmental parameters.

Unfortunately, due to marketing and globalisation, vernacular materials and techniques are often considered as "oldfashioned" and "for the low income groups in a society" in spite of their superior sustainability. Therefore, research should now focus on what the authors of this paper would call "Vernacular Construction 2.0", merging tried and proven vernacular techniques with state of the art scientific materials knowledge, in order to confer the capacity to provide habitat with the same attractiveness, comfort, and real estate value as modern contemporary habitat to selected traditional materials and techniques without giving up what makes the essence of vernacular: to be local, economical, efficient, and indefinitely recyclable.
Construction with compacted raw earth is probably one of the best examples where this approach could be implemented. At high density, soil is a natural concrete with remarkable hygrothermal properties and an exceptionally low environmental impact [60]. Recent developments have shown that almost all modern construction techniques used with concrete - including self-placing casting or 3D printing $[60,61]-$ can be used with raw earth also. Its Achilles' heel is low wet strength [62]. Rather than correcting this with addition of cement and ruining its environmental advantage and gaining only moderate strength [4, 19], a better solution would be to find sustainable solutions [63]. Lime and natural fibres can enhance the performance [64], also coatings and architectural protective concepts can be a solution.

Another interesting research area is shell structures that naturally avoid the tensile stresses, which typically cause most challenges to materials. Africa has chiliads of experience with shell structures $[65,66]$, and a revisit of their structural advantages in combination with vernacular materials supplemented with a state of the art knowledge based approach could become a step into the future rather than in the past. However, this calls for urgent trans-disciplinary research between engineers, material scientists and architects [37,38].

\section{Robustness and application safety}

Construction sectors in Africa are often highly influenced by developed countries. Therefore, some, mostly urban residential areas, have been developed based on foreign models without consideration of the local population needs. Practitioners also report that site planning is often not well adhered to or ignored altogether, which adds up to the problem and additionally compromises the structural integrity of buildings. As a result of not well coordinated implementation, often entire stretches in cities are unsightly, 
and the felling of large numbers of trees that comes along with it results in lack of fresh air. The aftermath of constructions in Africa may completely alter the green ground cover of the continent. Waste generated in construction sites are often not well disposed of so that dams and natural water bodies such as rivers and lakes serve as a source for the wastes. As part of urgently required regulatory guidelines, proper disposal or recycling of construction materials need to be addressed in future regulative research.

Another major challenge in Africa is the lack of reliability of the supply chains. Lack quality infrastructure (QI) [67] and testing institutions along with materials variability reduce the robustness of construction technologies with direct consequences for the serviceability and durability of structures, and eventually enormous societal costs. The financial means to establish a functioning QI are still limited in most African countries. However, this can be an advantage, since overregulation is often detrimental to the urgently required innovation. Therefore, African researchers should develop priority areas where QI systems can be developed effectively and at given cost limitations. In this context, researchers should collaborate with public bodies and standardisation bodies. One focus area should be the safety of structures during construction, since reportedly a high number of structures already fail while under construction [23].

In order to address the issue of quality control and site observation the focus of research should be put on implementation of smart mobile phone services and quality control tools. The African population is relatively young, compared to the rest of the world, and shows a high affinity to uptake of digital tools. Web-based quality control tools for the optimisation of mixture compositions, the usage of chemical admixtures or for the conformity and quality control of concrete production [68], up to adequate waste disposal seem to be promising developments. Control chart based systems, e.g. Shewhart or Cusum [68-71], the latter of which has already been established in the conformity control of ready-mixed concrete in countries like South Africa and Kenya, can become bottom-up game changers. By providing decision making tools for both customer and provider, thus, effectively creating a balance between "over-control" and "under-control" in steady production processes, excessive material strength can be avoided without compromising the safety level of the production.

\section{Socio-economic aspects of construction}

While the collaboration between civil engineering and architecture seems to be obvious, the link to disciplines in the social sciences and humanities is evasive and often neglected, although construction inevitably interferes with the past and future of the social environment. Architecture, material choices, and building density define urban and rural environments, they can also enhance or inhibit social interactions between gender, income, religious, or ethnic groups [72]. The rapid urbanisation in Africa offers a unique opportunity for development to be more inclusive, and to consider the unique social and cultural needs of people with varying economic statuses across different genders and religious groups. Nevertheless, today on average around $60 \%$ of the urban settlers live in underprivileged, improvised, and neglected settlements.

This brings to mind the issue of informal settlements and its deleterious consequences on the quality of life and the built environment in African cities. In fact, several cases of demolition of informal housing leading to homelessness of many residents have been observed in Nigeria, South Africa, Kenya and other African countries [73, 74]. As observed by Alabi [75], many of the informal settlements that had sprung up contravened local planning regulations, hence the cases of demolition. The persistence of informal settlements in African cities is due to housing deficits and poverty, among other factors. Thus, the use of environmentally friendly low-cost materials acceptable to the building planning and control authorities may be a prescription for improvement in the quality of construction materials for formal or informal housing in Africa where the governments have not been able to adequately provide affordable housing units for the lowincome groups. At the ISEE-Africa conference 2019 [17], several workshops concluded that the label "low-cost" in this context has a negative connotation and is detrimental for the market acceptance of sustainable, materials-saving solutions. In order to avoid false public perception of environmentally friendly materials, sustainable technologies should be integrated more explicitly in curricula at universities and institutions for professional development [59].

Construction also needs to consider the economic benefits accruable to all stakeholders in the construction process i.e. value for money to the client, cost efficiency for developers, reduced maintenance and replacement cost for end-users, and livelihood opportunities for community dwellers [76]. Achieving the desired socio-economic balance in the construction industry will require intentional multidisciplinary research and collaborative learning between engineers, architects, and other professionals from the social sciences and humanities, which today is not always the case $[72,77]$. Such interdisciplinary research would stand out in the world and could make research institutions in Africa pioneers and leaders in sustainable materials and construction technology.

\section{Durability}

A most important aspect in all construction in Africa is durability - from design, specification, construction and maintenance viewpoints. This is important to ensure that the capital investments (e.g. roads, bridges, jetties, etc.) by African governments are worthwhile both in the short- and long-term. There are a number of potential durability risks for concrete structures on the African continent. These deterioration processes are exacerbated by the largely warm and humid African climate, particularly in SSA, and the long coastline on the African continent. Steel corrosion is the main cause of durability failure in reinforced concrete structures; it is caused by ingress of carbon dioxide (carbonation-induced) or chlorides (chloride-induced) in concrete with the latter being more pernicious than the former $[78,79]$ 
Concrete structures in coastal cities like Lagos, Dar es Salaam, Cape Town, Mombasa and Mogadishu are exposed to marine environments which trigger chloride-induced steel corrosion especially if concrete quality is low, cover to steel is inadequate, and monitoring and repair strategies are poor. Apart from steel corrosion, other potential durability risks for new and existing concrete structures in SSA include sulphate attack, alkali-aggregate reaction, soft water attack and microbial- or bacterial-induced degradation such as corrosion of concrete in wastewater reticulation systems [80,81]. With the population growth and increasing industrialisation more wastewater will be generated. Other potential durability issues are linked to Aggregate Alkali Reaction, most dominantly Alkali Silica Reaction (ASR). Since high temperature and humid conditions are precondition for the deteriorating gel to form from the aggregate reaction, the African climate can boost ASR [82, 83]. To date, most African countries have neither classified available aggregate sources nor put guidelines in place. With continued urbanisation in SSA, durability risks will undoubtably increase exponentially $[72,73]$.

It is therefore incumbent on the researchers and stakeholders in Africa to be actively involved in the development of local solutions to tackle these durability problems, and/or adapt existing solutions to meet the local needs using locally sourced materials and technologies. These solutions will involve but are not limited to:

- characterization of locally available alternative construction materials (cements, aggregates, surface coatings, fibres and admixtures);

- application of locally-adapted performance-based durability design, specification and construction approaches as opposed to using the traditional purely prescriptive approaches $[84,85]$. South Africa, which uses a suite of three locally-developed durability index tests (oxygen permeability, water sorptivity and chloride conductivity [86], is a typical example in Africa in this regard, and

- Incorporation of durability-related content in the curricula for engineering and the built environment programmes in higher education institutions expose and sensitize learners to the need for durable structures.

\section{Adaption to growth}

The rapid urbanisation in Africa is inevitable and will coin future developments and perspectives all over the continent much more than any other relevant research topic. Despite the tremendous urban growth, it must not be forgotten that in most African countries rural areas also grow, albeit less rapidly. Therefore, research should focus more on possible synergies between urban growth and rural development. Many agro-based materials that are sourced from rural areas can be converted to structural materials for urban use $[40,87$, 88]. This way, urban growth can enhance livelihoods in rural areas, thus triggering development and employment opportunities. Ideally, circular concepts should be studied, evaluated and promoted depending on the specific boundary framework. Reasonable technology combinations, e.g. pyrolysis and vertical shaft kiln, can derive organic admixtures, bio-based binders, LC3 and bricks in a combined process chain with minimum carbon emissions [8]. Depending upon the framework, alternative processes can be developed, but this requires intensive interdisciplinary research.

Eventually, the predictability of the urban and rural growth requires the development of settlements that are sustainable for the people, this includes hybrid traffic concepts including a strong focus on non-motorised traffic, the development of urban livelihoods in synergy with climate friendly technologies such as urban mining and urban farming.

The development of these concepts requires interdisciplinary research activities. An important research focus should be the scalability within the given framework. In this context it will be important to look at the diversity of Africa in its entirety. Concepts that may be reasonable in West Africa may not be automatically applicable in East Africa - at least not without adaption. The research in tailored best-practice solutions, thus, should be encouraged regionally and in collaboration with local industry, politics, and societies. The fact that construction is labour-intensive is an added value to the extent that an investment in construction could result in employment opportunities for different categories of artisans and professionals who are inevitably needed for the supply of materials or conversion of materials in the construction value chains ranging from acquisition of land to completion of construction projects.

\section{Closing remarks}

Outside Africa, the diversity and versatility of the continent is often not realistically perceived and appreciated. The dimensions and the complexity call for a vast variety of solutions to tackle the recent and future challenges in construction. Since Africa plays a central role in mitigating negative climate effects caused by construction activities, intensive research actions are required in Africa for the benefit of the entire world. Unfortunately, the research budget has been low on the continent and is predicted to stay relatively low.

Therefore, collaboration between African researchers is needed to focus on research topics that are of eminent importance to addressing local needs. In Africa, this means more focus has to be put on climate friendly construction materials and technologies to accompany the rapid urbanisation. Africa's outstanding starting position, its huge deposits of promising yet not well studied materials and a generation of agile researchers that is ready for change, the potentials to convert African construction business to an innovation and sustainability driven export hit.

Some relevant topics that require more research focus have been presented and discussed in this paper. They can be distinguished between materials, construction technology and maintenance. A summary is given in Fig. 4. 


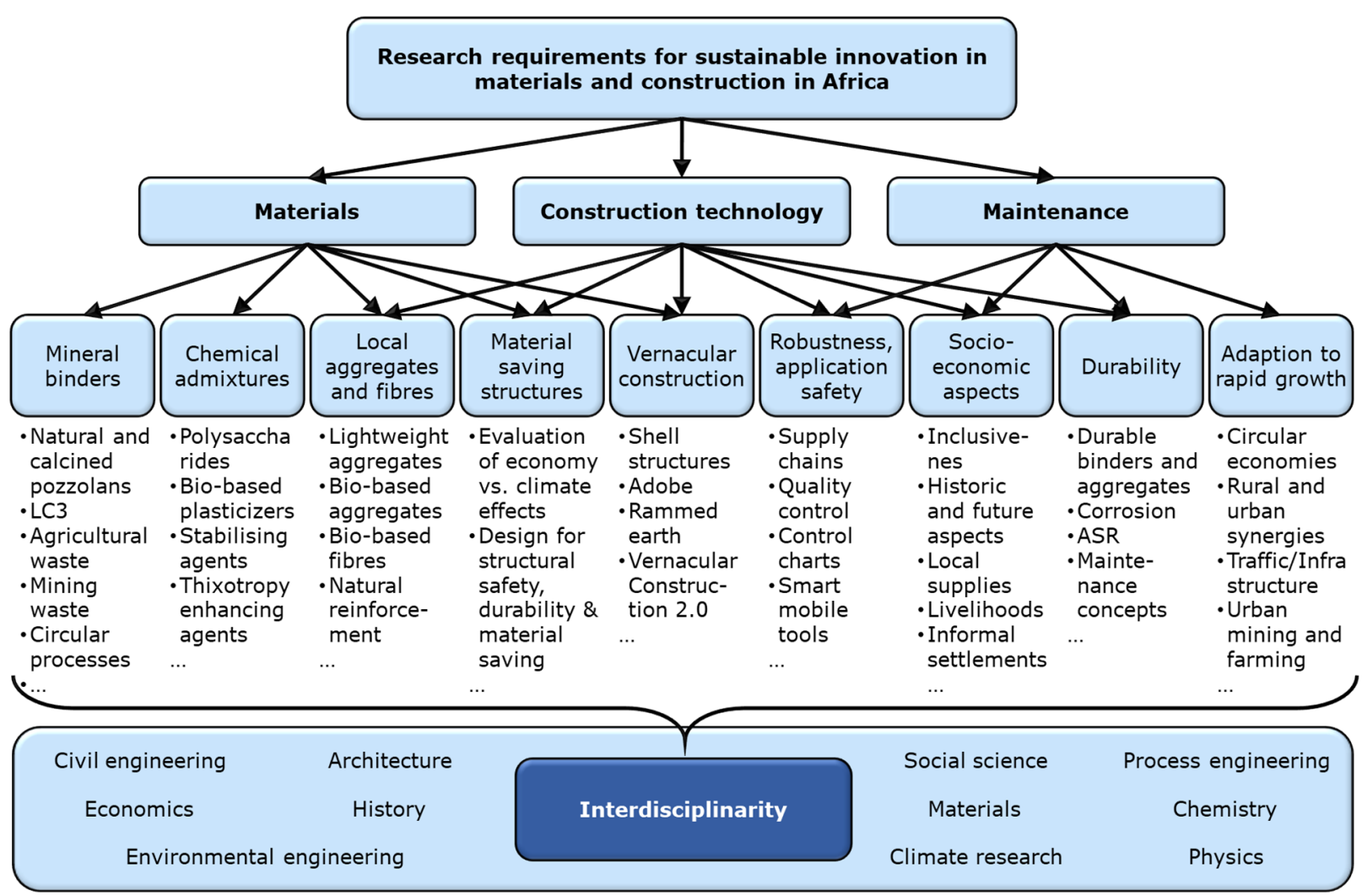

Figure 4. Summary of climate and society relevant trans-disciplinary research focal areas related to challenges and potentials in construction in Africa.

\section{References}

[1] K. Carstensen, O. Rapf, A blueprint for a climate friendly cement industry. in: WWF (Ed.) WWF, Nürnberg, Germany, 2008.

[2] CEMBUREAU, Cement \& concrete: key facts \& figures. in: t.E.c. association (Ed.) 2015

[3] P. Edwards, The Rise and Potential Peak of Cement Demand in the Urbanized World. 2016. http://cornerstonemag.net/the-rise-andpotential-peak-of-cement-demand-in-the-urbanized-world/. (Accessed 10.05.2020.

[4] K. Scrivener, V.M. John, E.M. Gartner, Eco-efficient cements: Potential economically viable solutions for a low-CO2 cement-based materials industry. in: H. A (Ed.) United Nations Environment Programme, Paris, 2017 (Revised edition). https://doi.org/10.1016/i.cemconres.2018.03.015

[5] L. Barcelo, J. Kline, G. Walenta, E. Gartner, Cement and carbon emissions. Mater Struct (2014) 47(6): 1055-1065. https://doi.org/10.1617/s11527-013-0114-5

[6] UN, World Population Prospects: The 2015 Revision. 2015. http://www.un.org/en/development/desa/news/population/2015report.html. (Accessed 10.05.2020).

[7] JCSS, RILEM, IABSE, fib, CIB, ECCS, IASS, Global Consensus on sustainability in the Built Environment, Liason Committee of the JCSS, 2020, http://globe.rilem.net

[8] W. Schmidt, K. Olonade, N. Radebe, F. Zando, V. Ssekamatte, Rural employment perspectives from sustainable, green construction materials for urban development - in press, publication date 6/2020. Rural 21 (2020) (2/20): 36-38.

[9] W. Schmidt, N.W. Radebe, M.O. Otieno, K.A. Olonade, S. Fataei, F. Mohamed, G.L. Schiewer, M. Thiedeitz, A. Tetteh Tawiah, R. Dauda, G. Bassioni, M. Telong, A. Rogge, Challenges, opportunities and potential solution strategies for environmentally and socially responsible urban development of megacities in Africa. 3RD RILEM Spring Convention 2020 - ambitioning a sustainable future for built environment: comprehensive strategies for unprecedented challenges, RILEM, Guimaraes, Portugal, 2020, in press.
[10] D. Messner, J. Schellnhuber, S. Rahmstorf, D. Klingenfeld, The budget approach: A framework for a global transformation toward a lowcarbon economy. JOURNAL OF RENEWABLE AND SUSTAINABLE ENERGY (2010) 2, $031003031003-1$ - 031003-14 https://doi.org/10.1063/1.3318695

[11] https://www.indexmundi.com/facts/indicators/EN.ATM.CO2E.PC. (Accessed June 2020).

[12] https://www.indexmundi.com/facts/indicators/SP.POP.TOTL/rankin gs. (Accessed June 2020).

[13] https://www.indexmundi.com/facts/indicators/IP.JRN.ARTC.SC. (Accessed June 2020).

[14] Developing partnerships. Nature (2015) 527(7577): S60-S63. https://doi.org/10.1038/527S60a

[15] https://www.indexmundi.com/facts/indicators/NY.GDP.PCAP.KD/ra nkings. (Accessed June 2020).

[16] https://www.indexmundi.com/facts/indicators/GB.XPD.RSDV.GD.ZS (Accessed June 2020)

[17] W. Schmidt, F. Falade, A. Rogge, R. Tchitnga, ISEE - Innovation, Science, Engineering, Education (Post-conference edition) www.isee-africa.com. post-conference edition ed., Bundesanstalt für Materialforschung und -prüfung (BAM), Berlin, Germany, 2019.

[18] W. Schmidt, A. Radlińska, C. Nmai, A. Buregyeya, W.L. Lai, S. Kou, Why does Africa need African concrete? An observation of concrete in Europe, America, and Asia - and conclusions for Africa. International Conference on Advances in Cement and Concrete Technology in Africa, Johannesburg, South Africa, 2013, 1139-1148.

[19] B.L. Damineli, F.M. Kemeid, P.S. Aguiar, V.M. John, Measuring the eco-efficiency of cement use. Cem Concr Compos (2010) 32(8): 555562. https://doi.org/10.1016/i.cemconcomp.2010.07.009

[20] G. International Labour Office, Women and Men in the Informal Economy: A Statistical Picture. in: G. International Labour Office (Ed.) International Labour Organization, 2018.

[21] S. Sánchez Berriel, A. Favier, E. Rosa Domínguez, I.R. Sánchez Machado, U. Heierli, K. Scrivener, F. Martirena Hernández, G. Habert, Assessing the environmental and economic potential of Limestone Calcined Clay Cement in Cuba. J Cleaner Prod (2016) 124 361-369. https://doi.org/10.1016/i.jclepro.2016.02.125 
[22] H.C. Uzoegbo, D. Bjegovic, W. Schmidt, W. Kitobo, SCM Potential in Africa. World Cement (2012) (8).

[23] W. Schmidt, N.S. Msinjili, H.-C. Kühne, Materials and technology solutions to tackle the challenges in daily concrete construction for housing and infrastructure in sub-Saharan Africa. African J Sci Technol Innov Dev (2018) 1-15. https://doi.org/10.1080/20421338.2017.1380582

[24] K. Olonade, A.M. Olajumoke, A.O. Omotosho, F.A. Oyekunle, Effects of sulphuric acid on the compressive strength of blended cementcassava peel ash concrete. Construction Materials and Structures (2014) 764-771.

[25] N.S. Msinjili, W. Schmidt, B. Mota, S. Leinitz, H.-C. Kühne, A. Rogge, The effect of superplasticizers on rheology and early hydration kinetics of rice husk ash-blended cementitious systems. Constr Build Mater (2017) 150 511-519. https://doi.org/10.1016/j.conbuildmat.2017.05.197

[26] W. Wilson, A. Tagnit-Hamou, Workability and Hydration of Superplasticized Cementitious Mixtures with Rice Husk Ash. Aci Mater J (2014) 111(5): 491-500. https://doi.org/10.14359/51687100

[27] J.M. Paris, J.G. Roessler, C.C. Ferraro, H.D. DeFord, T.G. Townsend, A review of waste products utilized as supplements to Portland cement in concrete. J Cleaner Prod (2016) 121 1-18. https://doi.org/10.1016/i.jclepro.2016.02.013

[28] G.C. Cordeiro, R.D. Toledo Filho, E.M.R. Fairbairn, Influence of Rice Husk and Sugar Cane Bagasse Ultrafine Ashes on Hydration Characteristics of Cement Based Pastes. 13th International Congress on the Chemistry of Cement, Madrid, Spain, 2011.

[29] O. Fadele, M. Otieno, Utilisation of supplementary cementitious materials from agricultural wastes: a review. Proceedings of the Institution of Civil Engineers - Construction Materials (2020) 1-7. https://doi.org/10.1680/jcoma.19.00098

[30] P. van Straaten, The Geological Basis of Farming in Africa. Springer, Dordrecht, 2011, 31-47. https://doi.org/10.1007/978-90-481-254323

[31] L. Dvorkin, N. Lushnikova, M. Sonebi, Dry pack mortars for selflevelling floor compounds based on $\beta$-hemihydrate and modified phosphogypsum binder. Proceedings of the 3rd International Conference on Bio-Based Building Materials (ICBBM), Belfast, UK, 2019, 97-101.

[32] E. Saadaoui, N. Ghazel, C. Ben Romdhane, N. Massoudi, Phosphogypsum: potential uses and problems - a review. Int J Env Stud (2017) 74(4): 558-567. https://doi.org/10.1080/00207233.2017.1330582

[33] M.C. Vieira, D. Klemm, L. Einfeldt, G. Albrecht, Dispersing agents for cement based on modified polysaccharides. Cem Concr Res (2005) 35(5): 883-890. https://doi.org/10.1016/j.cemconres.2004.09.022

[34] A. Peschard, A. Govin, P. Grosseau, B. Guilhot, R. Guyonnet, Effect of polysaccharides on the hydration of cement paste at early ages. Cem Concr Res (2004) 34(11): 2153-2158. https://doi.org/10.1016/i.cemconres.2004.04.001

[35] S. Chandra, L. Eklund, R.R. Villarreal, Use of Cactus in Mortars and Concrete. Cem Concr Res (1998) 28(1): 41-51. https://doi.org/10.1016/S0008-8846(97)00254-8

[36] J. Plank, Applications of biopolymers and other biotechnological products in building materials. App Microbiol Biotechnol (2004) 66(1): 1-9. https://doi.org/10.1007/s00253-004-1714-3

[37] W. Schmidt, I. Tchetgnia Ngassam, K. Olonade, Mbugua, R, H.-C. Kühne, Plant based chemical admixtures - potentials and effects on the performance of cementitious materials. RILEM Tech Lett (2018) 3 124-128. https://doi.org/10.21809/rilemtechlett.2018.83

[38] R. Mbugua, R. Salim, J. Ndambuki, Effect of Gum Arabic karroo as a Water-Reducing Admixture in Concrete. Mater (2016) 9(2). https://doi.org/10.3390/ma9020080

[39] R. Mbugua, S. Ramadhan, J. Ndambuki, Durability and strength performance of concrete with gum acacia Karoo as bio admixture cured at different temperatures. in: N.S. Msinjili, W. Schmidt (Eds.), KEYS Knowledge Exhcange for Young Scientists: Valorisation of Industrial By-products for Sustainable Cement and Concrete Construction - Improvement of Solid Waste Management, BAM, Accra, Ghana, 2016, 89-93.

[40] W. Schmidt, K.A. Olonade, R. Mbugua, F.J. Lenz, I.L. Tchetgnia Ngassam, Bio-Based Rheology Modifiers for High Performance Concrete - Possible Modes of Actions and Case Study for Cassava Starch in West Africa. 3rd International Conference on the Application of Superabsorbent Polymers (SAP) and Other New Admixtures Towards Smart Concrete, Skukuza Camp, South Africa, 2019, 158-166. https://doi.org/10.1007/978-3-030-33342-3 17

41] W. Schmidt, I.N. Tchetgnia Ngassam, R. Mbugua, K.A. Olonade, Promising Bio-Based Rheology Modifying Agents for Concrete. Rheologie komplexer Fluide: Theorie, Experiment und Anwendung. 2016.

[42] B. Benabed, L. Azzouz, E.-H. Kadri, S. Kenai, A.S.E. Belaidi, Effect of fine aggregate replacement with desert dune sand on fresh properties and strength of self-compacting mortars. J Adhes Sci Technol (2014) 28(21): 2182-2195. https://doi.org/10.1080/01694243.2014.950625

[43] S. Amziane, M. Sonebi, Overview on Biobased Building Material made with plant aggregate. RILEM Tech Lett (2016) 1: 31-38. https://doi.org/10.21809/rilemtechlett.2016.9

[44] M. Sonebi, S. Wana, S. Amziane, J. Khatib, Investigation of the mechanical performance and weathering of hemp concrete. First International Conference on Bio-based Building Materials, ClermontFerrand, France, 2015.

[45] 45] W. Schmidt, N.S. Msinjili, S. Pirskawetz, H.C. Kühne, Efficiency of high performance concrete types incorporating bio-materials like rice husk ashes, cassava starch, lignosulfonate, and sisal fibres. First International Conference on Bio-based Building Materials, ClermontFerrand, France, 2015.

[46] R.D. Toledo, K. Ghavami, G.L. England, K. Scrivener, Development of vegetable fibre-mortar composites of improved durability. Cem Concr Comp (2003) 25(2): 185-196. https://doi.org/10.1016/S0958-9465(02)00018-5

[47] B. Ndazi, J. Tesha, E. Bisanda, Some opportunities and challenges of producing bio-composites from non-wood residues. J Mater Sci (2006) 41(21): 6984-6990. https://doi.org/10.1007/s10853-0060216-3

[48] B. Krobba, M. Bouhicha, S. Kenai, L. Courard, Formulation of low cost eco-repair mortar based on dune sand and Stipa tenacissima microfibers plant. Constr Build Mater (2018) 171 950-959. https://doi.org/10.1016/j.conbuildmat.2018.03.200

[49] M. Lobovikov, S. Paudel, M. Piazza, H. Ren, J. Wu, World bamboo resources - A thematic study prepared in the framework of the Global Forest Resources Assessment 2005. in: FAO (Ed.) Rome, 2007.

[50] Javadian, I. Smith, D. Hebel, Application of Sustainable BambooBased Composite Reinforcement in Structural-Concrete Beams: Design and Evaluation. Mater (2020) 13: 696 https://doi.org/10.3390/ma13030696

[51] [51] K. Ghavami, Bamboo as reinforcement in structural concrete elements. Cem Concr Compos (2005) 27(6): 637-649. https://doi.org/10.1016/j.cemconcomp.2004.06.002

[52] W. Yao, Z. Li, Flexural behavior of bamboo-fiber-reinforced mortar laminates. Cem Concr Res (2003) 33(1): 15-19. https://doi.org/10.1016/S0008-8846(02)00909-2

[53] M. Frías, H. Savastano, E. Villar, M.I. Sánchez de Rojas, S. Santos, Characterization and properties of blended cement matrices containing activated bamboo leaf wastes. Cem Concr Compos (2012) 34(9): 1019-1023. https://doi.org/10.1016/j.cemconcomp.2012.05.005

[54] E. Villar-Cociña, E.V. Morales, S.F. Santos, H. Savastano, M. Frías, Pozzolanic behavior of bamboo leaf ash: Characterization and determination of the kinetic parameters. Cem Concr Compos (2011) 33(1): 68-73. https://doi.org/10.1016/j.cemconcomp.2010.09.003

[55] W. Schmidt, J. Anniser, K. Manful, A sustainability point of view on horizontal and vertical urban growth. in: W. Schmidt (Ed.), ISEE Innovation, Science, Engineering, Education (Post-conference edition), Bundesanstalt für Materialforschung und -prüfung (BAM), Berlin, Germany, 2019, 189-193.

[56] P. Purnell, Material Nature versus Structural Nurture: The Embodied Carbon of Fundamental Structural Elements. Env Sci Technol (2012) 46(1): 454-461. https://doi.org/10.1021/es202190r

[57] G. Habert, N. Roussel, Study of two concrete mix-design strategies to reach carbon mitigation objectives. Cem Concr Compos (2009) 31(6): 397-402. https://doi.org/10.1016/j.cemconcomp.2009.04.001

[58] A.P. Fantilli, O. Mancinelli, B. Chiaia, The carbon footprint of normal and high-strength concrete used in low-rise and high-rise buildings. Case Studies in Construction Materials (2019) 11 e00296. https://doi.org/10.1016/i.cscm.2019.e00296

[59] W. Schmidt, M. Alexander, V. John, Education for sustainable use of cement based materials. Cem Concr Res (2018) 114 103-114. https://doi.org/10.1016/j.cemconres.2017.08.009

[60] H. Van Damme, H. Houben, Earth concrete. Stabilization revisited. Cem Concr Res (2018) 114 90-102. https://doi.org/10.1016/i.cemconres.2017.02.035 
[61] A. Perrot, D. Rangeard, E. Courteille, 3D printing of earth-based materials: Processing aspects. Constr Build Mater (2018) 172 670676. https://doi.org/10.1016/j.conbuildmat.2018.04.017

[62] A.T.M. Marsh, A. Heath, P. Walker, B.V.V. Reddy, G. Habert, Discussion of "Earth concrete. Stabilization revisited". Cem Concr Res (2020) 130: 105991. https://doi.org/10.1016/j.cemconres.2020.105991

[63] H. Van Damme, H. Houben, Reply to the discussion of the paper "Earth Concrete. Stabilization Revisited" by A.T.M. Marsh, A. Heath, P. Walker, B.V. Venkatarama Reddy, and G. Habert. Cem Concr Res (2020) 130105992. https://doi.org/10.1016/j.cemconres.2020.105992

[64] W. Benhaoua, K. Grine, S. Kenai, Performance of Stabilized Earth with Wheat Straw and Slag. MRS Advances (2020) 5(25): 1285-1294. https://doi.org/10.1557/adv.2020.174

[65] M. Gohnert, I. Bulovic, R. Bradley, A Low-cost Housing Solution: Earth Block Catenary Vaults. Structures (2018) 15 270-278. https://doi.org/10.1016/j.istruc.2018.07.008

[66] T. O. Adekunle, T.S. Odeyale, Innovative and sustainable local material in traditional African architecture - Socio cultural dimension. in: D. D'Ayala, E. Fodde (Eds.), Structural Analysis of Historic Construction: Preserving Safety and Significance, Taylor and Francis, 2008, 991-998. https://doi.org/10.1201/9781439828229.ch113

[67] W. Schmidt, I. Tchetgnia Ngassam, G. Breitschaft, S. Virchow, Challenges of the growing African cement market - environmental issues, regulative framework, and quality infrastructure requirements. MATEC Web of Conferences, Les Ulis, 2018, 01014-101014-8. https://doi.org/10.1051/matecconf/201814901014

[68] [68] W. Schmidt, H.-C. Kühne, Cusum charts for the control of the slump flow of self-compacting concrete in a steady production process. Proceedings of the 8th RILEM Symposium on SelfCompacting Concrete, Washington, USA, 2016, 283-294.

[69] W. Schmidt, H.-C. Kühne, EN 206:2014: Cusum method or mean value criterion? / EN 206:2014: Kusum-Verfahren oder Mittelwertkriterium? BFT international (2014) 80(12): 24-31.

[70] Monitoring concrete strength by the cusum system. The Concrete Institute, Midrand, South Africa, 2013.

[71] R. Caspeele, L. Taerwe, Combined production and conformity control of concrete with acceptance cusum control charts. Proceedings of the 7th International Probabilistic Workshop, Dresden, Germany, 2009.

[72] N.D. Serumaga-Musisi, The Griot Introspect - Whose Utopia is it Anyway? 2018, https://medium.com/@madugian/the-griotintrospect-cbd39de7ac65.

[73] M. Huchzermeyer, Pounding at the tip of the iceberg: The dominant politics of informal settlement eradication in South Africa. Politikon (2010) 37(1): 129-148 https://doi.org/10.1080/02589346.2010.492153

[74] E. Amakihe, Forced eviction and demolition of slum: A case study of the Makoko slum in Lagos, Nigeria. J Urban Regen Renew (2017) 10(4): 400-408

[75] M. Alabi, Political economy of urban housing poverty and slum development in Nigeria. East Afr Soc Sci Res Rev (2018) 34(2): 59-79. https://doi.org/10.1353/eas.2018.0014

[76] P. Tunji-Olayeni, K. Kajimo-Shakantu, E. Osunrayi, Practitioners' experiences with the drivers and practices for implementing sustainable construction in Nigeria: a qualitative assessment. Smart and Sustainable Built Environment (2020), in print. https://doi.org/10.1108/SASBE-11-2019-0146

[77] M. Barucker-Sturzenbecher, W. Schmidt, Learning from the future how children of Mukuru fancy the city of tomorrow. ISEE Africa Innovation, Science, Engineering, Education, Nairobi, Kenya, 2019, 194-197.

[78] M. Santhanam, M. Otieno, Chapter 5: Deterioration of concrete in the marine environment. in: M. Alexander (Ed.), Marine Concrete Structures: design, durability and performance, Woodhead Publishing, 2016, 135-149. https://doi.org/10.1016/B978-0-08-100081-6.00005-2

[79] M. Otieno, Durability of steel reinforced concrete structures in the marine environment - what is the way forward? Kenya Engineer Journal of the Institution of Engineers of Kenya (2018) 39(5): 22-25.

[80] K.A. Olonade, A Review of Effects of Wastewater on Reinforced Concrete Structures in Nigeria. Nigerian Journal of Technology (2016) 35(2): 234 - 241. https://doi.org/10.4314/njt.v35i2.2

[81] M. Otieno, M. Alexander, J. Du Plessis, Soft water attack on concrete tunnel linings in the Ingula pumped storage hydropower scheme: assessment of concrete resistance and protection. Journal of the South African Institution of Civil Engineering (SAICE) (2017) 59(3): 57 67. https://doi.org/10.17159/2309-8775/2017/v59n3a7
[82] J. Lindgård, Ö. Andiç-Çakır, I. Fernandes, T.F. Rønning, M.D.A. Thomas, Alkali-silica reactions (ASR): Literature review on parameters influencing laboratory performance testing. Cem Concr Res (2012) 42(2): 223-243. https://doi.org/10.1016/j.cemconres.2011.10.004

[83] I. Sims, P. Nixon, RILEM recommended test method AAR-1: Detection of potential alkali-reactivity of aggregates-Petrographic method. Mater Struct (2003) 36(7): 480-496. https://doi.org/10.1007/BF02481528

[84] M. Otieno, From prescriptive to performance-based durability design and specification of concrete structures. Proceedings of the 18th International Conference on Non-conventional Materials and Technologies (IC-NOCMAT), Nairobi, Kenya, 2019, 334-346.

[85] M. Otieno, A case for the need to incorporate durability in the design and construction of RC structures. Kenya Engineer - Journal of the Institution of Engineers of Kenya (2018) 39(1): 32-38.

[86] T.C. Institute, Durability Index Testing Procedure Manual. 2018.

[87] K.A. Olonade, Benefit - cost analysis of recycling solid wastes in concrete: a case study of cassava peels in Nigeria. Nigerian Research Journal of Engineering and Environmental Sciences (2017) 1(2): 1-8.

[88] W. Schmidt, M.J. Barucker-Sturzenbecher, Bio-based concrete (https://vimeo.com/310549146). Berlin, 2019, 7:51. 